\title{
The adoption and concerns of e-finance in Malaysia
}

\author{
Kogilah Narayanasamy • Devinaga Rasiah • \\ Teck Ming Tan
}

Published online: 8 July 2011

(C) The Author(s) 2011. This article is published with open access at Springerlink.com

\begin{abstract}
Technological advancement has brought a whole new way of delivering financial services around the world. E-finance industry in Malaysia has grown rapidly with the help of internet and conducting financial services are far easier now if compared to last time. Internet provided a new medium or channel in delivering financial services. However, there are also risks and challenges when using electronic finance. A total of 100 respondents had been targeted in completing this study. Survey method was utilized in collecting respondent's opinion and perception to test the variables. The target was companies which used electronic finance in delivering their services. Interviews were also conducted and relevant tests conducted which provided evidence to support the hypotheses for this study. It was found that e-finance was affected by security, revenue and cost dimensions, and technology architecture with the adoption of global technology.
\end{abstract}

Keywords E-finance $\cdot$ Security $\cdot$ Banking $\cdot$ Internet $\cdot$ Technology

\section{Introduction}

So, what exactly is e-finance? The answer to that may vary. According to the United Nations Conference on Trade and Development (UNCTAD) [44], it was defined as, "that of financial services delivered through internet or online. E-finance includes online brokerage, banking, insurance, and other financial services." Others may define it

K. Narayanasamy · D. Rasiah (凶) · T.M. Tan

Multimedia University, Melaka Campus, Melaka, Malaysia

e-mail: devinaga.rasiah@mmu.edu.my

K. Narayanasamy

e-mail: kogilah@mmu.edu.my

T.M. Tan

e-mail: tmtan@mmu.edu.my 
as the use of internet technology in delivering financial services. Faegre and Benson [20], indicated that nonetheless, e-finance can simply be defined as financial services conducted through online or electronic communication and computation. In a similar study Allen, McAndrew and Strahan [1], highlighted that internet was the core foundation for the growth of e-finance in this technological era. Allen, Hawkins and Sato [2], mentioned that the combination of both internet and e-finance allowed the e-finance industry to grow on a fast pace. The growth has been very impressive with millions of users worldwide and it's still growing!

Berger et al. [7] mentioned that internet was a global phenomenon and so is efinance. E-finance is now emerging in a lot of countries such as Brazil, India, South Korea, United States and also Malaysia. Claessens et al. [12] indicated that the technological advancement had definitely accelerating the growing pace of e-finance, especially in the online banking/online broking industry. Internet banking is developing rapidly in South-East Asia countries, especially in Singapore, Thailand and Malaysia. E-finance grew faster in countries with strong telecommunication infrastructure, while slower in countries with weaker telecommunication infrastructure. Evans, and Schmalensee [19], indicated that it was because e-finance was mainly based on the internet functions, weak telecommunication infrastructure will restraint it from growing. Banks [4], showed that E-finance had allowed transformation to the financial markets, in which it no longer had the need of physical place, as many financial activities can be conducted online. OECD [41] showed that as a result, trading system is becoming global.

\section{Recent prospect and revolution of e-finance}

According to World Bank survey, it stated that the average online banking penetration for developing countries was closed in 5\% (World Bank 2001), and it's relatively higher for some countries. As for trade finance, it is still at an early and new stage in other parts of the world. Berger et al. [7], showed that in today s', e-finance was spreading around the globe through various channels, such as computers, mobile phones and kiosks. Frix [21] mentioned that through these various channels, financial services could be conducted with more efficient and relatively faster. Domowitz and Steil [17] indicated that besides that, e-finance also facilitated in the securities market industry where large market shares were quickly taken up by online trading services. The percentage of brokerage services provided online in industrial countries and emerging markets was 28 percent. In a similar study by Baxter [5] indicated that the reason behind the rapid acceptance of e-finance in securities market was because of the markets technology-driven nature and it helped in the changing of brokers easier for customers. Meanwhile, "The Business week [9]" highlighted that low costs to introduce and integrated brokerage services had further enhanced the growth of e-finance in securities market around the world.

Bedrikow [6], indicated that the internet technology served as the driving forces behind the evolution of e-finance. Gewei and Keesling [26] mentioned that they have always gone hand in hand through the changes and improvements of e-finance. Gewei and Keesling [22], showed that automated teller machines provided by financial institution played a major role as the leaders in developing and improving technological 
Table 1 Internet banking and telecommunications access in various economies

\begin{tabular}{lllll}
\hline Region/Country & $\begin{array}{l}\text { Percentage of } \\
\text { banks offering } \\
\text { online } \\
\text { banking (2000) }\end{array}$ & $\begin{array}{l}\text { Percentage of } \\
\text { bank customers } \\
\text { using online } \\
\text { banking (2000) }\end{array}$ & $\begin{array}{l}\text { Percentage of } \\
\text { inhabitants with } \\
\text { mobile }\end{array}$ & $\begin{array}{l}\text { Computers with IP } \\
\text { address connected to } \\
\text { the internet, per }\end{array}$ \\
\hline Australia & 90 & 4 & 29 & 10,000 people (1998) \\
Hong Kong (China) & 25 & $<2$ & 47 & 400 \\
India & 10 & $<1$ & 1 & 400 \\
Indonesia & 0 & 0 & 1 & 0 \\
Korea, Rep. of & 90 & 3 & 30 & 0 \\
Malaysia & 10 & $<1$ & 10 & 38 \\
Philippines & 15 & $<1$ & 2 & 18 \\
Singapore & 95 & 5 & 35 & 187 \\
Taiwan (China) & 10 & 0 & 22 & 48 \\
Thailand & 0 & 0 & 3 & 4 \\
\hline
\end{tabular}

Source: Credit Suisse First Boston Global Bank Team [14]; World Bank 2000b

innovations to assist the customers in delivering better services and also more efficient operations. Statistics from the Miniwatts Marketing Groups (November 2007), 1.262 billion or 19 per cent of world population had access to the internet. Global Electronic Finance [23] and [24] mentioned that the internet or technology was one of the key drivers to the evolution of e-finance. Baxter and William [5], showed that the other key drivers are globalization, regulations, entrepreneurship, capital and competitions. Hancock et al. [18] indicated that these factors have transformed the financial industry and thus affected the financial players, users, regulators and also investors.

After indentifying the problem statement of this research study, the research objectives were determined. The objectives are as the follows:

- To examine how the risk and challenges affect the e-finance industry.

- To find solutions to overcome the challenges.

- To find out how the internet contributed to the development and growth of e-finance.

- To identify the relationship between risk, challenges and the e-finance industry.

- To investigate which risk affected e-finance the most?

- To examine how the adoption of global technology to local requirements reduce the risk and challenge to e-finance industry.

\section{Literature review}

Boot and Thakor [8], indicated that there are a number of factors or challenges that affected or restrained the growth of e-finance. Global Electronic Finance [23] and [24], mentioned that the factors that are affected are security, revenue and cost dimensions, technology architecture and adapting global technology to local requirements. Credit 
Suisse First Boston, Global Bank Team (1999) stressed that by identifying these factors were very important in research projects because by finding out the factors or challenges, financial service providers could implement or come up with new solutions to cope with it.

\section{Security}

Dandapani [16] indicated that security and data privacy were extremely important for all countries. By conducting financial services online, Nieto [40] mentioned in an earlier study that it exposed the firm's operations to internal and external threats which have been a regular concern for regulators worldwide. Shahrokhi [43] mentioned that security and privacy are challenges faced by the financial regulators and financial services industry.

Security, pre-employment screening and on-going education have become relevant in today's technology driven environment, where an employee can email a massive amount of information and data with just a click of the mouse. For example, acting without supervision causes 7.2 billion in losses this month at Societe General of France, has shock Europe and the world. Claessens, Glaessner, and Klingebiel [10], highlighted that e-finance had made the consumer and investor to be protected against issues such as security, privacy and transparency.

According to Christiansen [13], security and safety voiced by prospective e-finance clients fell into five main categories that are related to the identity of the counterpart, the safety of the actual online transaction, the integrity of the information transmitted to the counterparts and the uninterrupted access to services. Christiansen [5], 5 security and safety categories are:

- Authentication of the e-finance counterpart. Customers needed to be safeguard against fraudulent service providers.

- Non-repudiation and accountability for e-finance transactions. Customers looked for guarantees that protected them against all transactions and that financial transaction data were secure from alteration.

- Adequate customer support. The customer needed to be convinced that mechanisms were in place to handle complaints and provide Quality support.

- Guaranteed business continuity. Customers undertaking large volume of transactions, particularly in $\mathrm{B} 2 \mathrm{~B}$ required continuous connection. E.g. No breakdowns of online services.

- Data integrity and confidentiality. General Public often looked to financial institutions to protect stored customer information against alteration and usage by unauthorized parties.

Dandapani [16] found that as the electronic mode of finance evolved rapidly across the globe; security and integrity concerns become acute. In a another study by Miskin and Strahan [37], Herbst [27] highlighted that consumer trust in Internet transactions and the security provided by online financial services were perceived to be marginal and might have been the prime deterrent in the adoption of e-financial services.

Other researchers such as Levinsohn [31, 32], Claessens, Glaessner, and Klingebiel [11] argued that both providers and consumers viewed this as a constraint and 
concern. Serious operational risks and potential liabilities were associated with security breaches in the transfer of funds or instructions and the actual theft of identification information over the Internet. Crowther [15] found that clients were apparently less concerned about the safety of the distribution channel when the transaction was limited to a transferring real time of a simple asset or liability.

\section{Revenue and cost dimensions}

McAndrews and Chris [36], mentioned that the revenue and cost dimension in finance industry is quite complex and very hard to determine. Unlike traditional models, web offered free products and services, different prices for the same product, and customer profiling. Since the internet is a new medium, therefore it was very hard to set the pricing function and hard to understand the value of providing features. Miskin and Strahan [37], mentioned that the growth of e-finance depended largely on the technology architecture, in other words technology had great impact on e-finance. Moore [39] indicated that it is because suitable and appropriate technical platform had accelerated its growth. For example, a basic information model with a relatively static information base would require routine technical maintenance and security to keep it operational (Shahrokhi [43]).

Shahrokhi [43] analyzed that the e-commerce revenue structure is quite complex, as the web has altered the concepts of pricing. The technology on which the financial service industry depends has become much cheaper, and in the past 20 years computer power has risen by a factor of 10,000 (World Bank 1999). Claessens, Glaessner, and Klingebiel [10] found that there were similar changes occurring in telecommunications. In the past 20 years, the cost of voice transmission circuits has fallen by a factor of more than 10,000 .

Christiansen [13] viewed that the advent of the internet had lowered the marginal cost but not necessary the average cost of reaching business counterparts thus, making the players to seek in boosting their earnings through two separate routes: (1) Stepping up in their efforts at penetrating highly profitable market segments; and (2) cutting cost by outsourcing parts of their value chain or replacing existing distribution channels. Subsequently, Shahrokhi [43] stated in their report that the revenue generated between B2B exchanges is a very complex issue.

UNCTAD [44] agreed that no doubt the internet has the potential to reduced financial transaction cost, but cost reduction potential has often been exaggerated or misinterpreted. Mor, Executive Director, ICICI Bank [38] had indicated that the cost dynamics of e-finance is quite complex, so in order to gain the full potential of cost reduction, it is extremely important that a fully automated system which is capable of straight-through processing was created. Claessens, Glaessner, and Klingebiel [11] and Christiansen [13] have similar view on the marginal cost of e-finance being much lower than those of traditional delivery channels. According to the three authors, each transaction costing only a few cents if compared to transactions at bank branches at $\$ 1$ or so, and automated teller machines (ATM) at $\$ 0.50$. Although there are significant upfront costs, in the medium term the online costs of delivering bank services will be much lower than, at least as low as those of today's most internet-advanced banks in Sweden. 
Faegre and Benson [20] argued that banking via the internet is dramatically cheaper than through other ways. A consumer transaction done at a branch cost about $\$ 1.07$, through mail $\$ 0.73$, by ATM $\$ 0.27$ and lastly the cheapest by internet which cost $\$ 0.01$ only. The implications for profit for those financial institutions that succeed or fail in e-finance are enormous. Christiansen [13] argued that cost cutting has begun in the retail distribution system. He further stressed that it can be observed that financial institutions prefer to keep their network of retail outlets to provide services to those non-online clients and also continue having physical presence to reassure online clients.

\section{Technology architecture}

Claessens, Glaessner, and Klingebiel [10] analyzed that internet and wireless communication technologies are having a profound effect on financial services. Researchers Allen, McAndrews and Strahan [1] had found that electronic communications technologies have been used in the banking sector for many years, particularly in interbank payment systems. Example, the Fedwire payment system is one of the early applications of electronic communication networks in financial industry. Shahrokhi [43] argued that the selection of the most appropriate technical platform for the e-finance model depends on nature of the business model itself. For example, routine technical maintenance and security is needed to keep a basic information model with static information base operating.

Allen, McAndrews and Strahan [1] stated that the electronic payment system have evolved over the decades. In the industrialized countries, dedicated telephone networks and mainframe computer systems are used to manage any payments, which are characterized by high volumes and values of payments. Thompson Financial (2001), had found that the number of bank offices has rise gradually over the past 20 years, but the number of ATMs has exploded, from 18,500 in 1980 to 324,000 by 2000 . Moreover, banks' special role in the payments system is declining as technology allows for the unbundling of payment and credit services. Thus authorities may want to separate payment from other credit services and allow free entry to the payments system Allen, McAndrews and Strahan, [1].

\section{Adapting global technology to local requirements}

Indjikian [28] mentioned that in order to ensure growth and stability of e-finance services, it is important to adapt global technology to local requirements. Allen [2] indicated that while Internet technologies are global and their core is standardized, their applications can and needed to be adapted to local circumstances. Kumar and Zekos [29] mentioned that internet offered the amazing capability to reconcile global uniformity and local flexibility. It facilitates cross border links but at the same time created new configurations of networks and clusters. Distinctions between proximity and remoteness remained highly pertinent, even if the distance under consideration became virtual rather than geographical. Shahrokhi [43] pointed out that similar to 
the report provided by UNCTAD [44], stating that while internet technologies were global and standardized, they had to adapt to local circumstances. The need to localize financial solution is even stronger and larger than e-finance in Small and Medium sized Enterprises. Hu, Ohshima, and Zhong [25] showed that the characteristic, financial structure, size, sartorial mix can vary considerably even within the same country or region.

\section{Relationship between e-finance and security}

Internet transactions involve "open" system, so they are very vulnerable to interception and fraud, which includes the access of information by unauthorized third parties. (At the same time, electronic audit trails will permit regulators to trace transactions more easily. But cryptographic techniques for ensuring transaction security are rapidly improving, and almost fully secure for consumer transactions (Claessens, Glaessner, and Klingebiel [10]). Hu, Ohshima, and Zhong [25] indicated that breaches of security and electronic fraud have many far-reaching and expensive implications, including undermining confidence in the e-financial systems, diminishing trust in online transactions and destroying regulatory integrity and institutional reputations.

The cost of e-fraud could potentially exceed billions of dollars and poses an enormous burden to the global financial system with a potential to cripple the international payments system (Dandapani [16]). World Bank (2002) reported that the internet makes illegal financial activities more accessible than ever. For example, in the United States, recent surveys have indicated that $57 \%$ of all hack attacks last year targeted financial institutions. Whereas in Asia, the financial industry is likewise the most targeted for computer attacks, followed closely by the high-tech sector. Given the open nature of the internet, transaction security is likely to emerge as the biggest concern for the actual and potential customer's of e-finance. Its management and control are crucial for business reputation and the promotion of consumer confidence as well as operational efficiency since transaction risk could create a barrier to market acceptance (Hu, Ohshima, and Zhong [25]).

\section{Relationship between e-finance and revenue and cost dimensions}

The Internet and any other technological advances have shrunk economies of scale in the production of financial services. The main financial service still exhibiting increasing returns to scale is the medium-size loan market, because large databases of credit history are required to build a credit-scoring model for medium-size clients, thus giving the larger lenders a potential competitive advantage (Claessens, Glaessner, and Klingebiel [10]. Technology cost savings were often hypothetical, marketing costs were actual expenditures that could cost between USD 150 and 300 per actual customer. While such costs could be justified in on-line broking (and as a result some new comers, such as e-trade or Ameritrade managed to gain sizeable market share), this was not the case for Internet banking (UNCTAD [44]). 
Lower transaction costs could increase competition for providers and cost savings for consumers. Online brokerage firms have been forced to radically restructure the way they deliver brokerage services to retain market share. Brokerage commissions and fees fell from an average of \$52.89 a trade in early 1996 to \$15.67 in mid-1998 and by mid-2000, some online brokerage services had reduced their commissions to zero (Claessens, Glaessner, and Klingebiel [10]).

\section{Relationship between e-finance and technology architecture}

Non-banking financial services such as brokerage, trading systems, some retail banking services, and new services such as bill presentment or even payment gateways for business-to-business (B2B) commerce are subject to less regulation. New entrants could easily innovate with new technology and could show limited or no earnings without raising supervisory concern. As they gained market share and consolidated their position, they started to diversify into more highly regulated banking services. For example is e-trade's recent acquisition of a bank to provide the full range of financial services to its retail clients (Claessens, Glaessner, and Klingebiel [10]).

IT has reduced barriers to entry, facilitating entry by non-financial entities and an increase in competition, predominantly in services traditionally provided by banks and brokerage firms. Financial service providers may abuse their market power through creating standards that lead to a dominant share of the market. Financial markets involving high network externalities include payment and trading systems and exchanges. New forms of abuse of market power in the form of network externalities are increasingly a matter of concern for regulators. Banks are not the sole participants in the payment system and also not the sole providers of information about borrowers (Zekos [45]).

\section{Relationship between e-finance and adapting global technology to local requirements}

The most successful e-finance story in developing countries, which includes such banks like ICICI, Itau or Bradesco, stresses their ability to respond to local requirements in terms of their product mix and delivery channels. Faegre and Benson [20] indicate that the need to localize the financial solution is even stronger for the e-finance for SMEs, which for the most part operate within a limited geographical area. Moreover, Internet technologies create an opportunity to develop strong links between SMEs in different countries. For example, a Tunisian start-up, Intelligent DSP, works with the New Delhi office of Analog Devices to develop remote monitoring services for electrical power meters. More broadly, successful e-commerce initiatives facilitate the emergence of new forms of business organizations such as virtual hubs and networks (UNCTAD [44]. 


\section{Theoretical framework}

The theoretical framework consists of four independent variables, which are revenue and cost dimensions, security, technology architecture, adapting global technology to local requirements and one dependent variable that is electronic finance (e-finance). Global Electronic Finance [23] and [24], mentioned that the internet had lowered the cost of conducting financial services and provides a new way of delivering the services. Allen et al. [1] argued that it had dramatically changed the whole financial industry around the world. The benefits of cheaper financial services would be shared by providers and consumers. With the advent of new types of intermediaries, such as aggregators, consumers can increasingly compare prices for financial services (Claessens, Glaessner, and Klingebiel [10]).

According to Sato and Hawkins [2], it is an irony that more efficient transmission and use of data, but statistic on e-finance itself is so lacking that analysis of development is difficult. Global Electronic Finance [23] and [24], indicated that there are many gaps in the knowledge about the current position which exacerbated the uncertainty about the nature and speed of future developments. Many researches had analyzed that the risks and challenges did not affect the growth and development of e-finance, either in a positive or negative way or both. Dandapani [16] indicated that however, most of the researches were done in countries like the United States, India and Japan. Therefore, hoping by utilizing and adopting these similar studies, this research paper is able to identify the relationship between these variables in the context of e-finance in Malaysia.

\section{Hypothesis development}

H1: There is an association between revenue and cost dimensions and e-finance.

Revenue and cost dimensions are one of the risks and challenges that affect the e-finance industry. Domowitz and Steil [17], mentioned that many financial services payments services, asset management services, underwriting, personal financial advice could see that revenue declined when they became subject to more competition from e-finance. Generally, the threat of entry had probably lowered the market value of incumbent banks and other financial service providers, suggesting that markets were expecting lower profits (Claessens, Glaessner, and Klingebiel [11]). It was very clear that internet was able to lower financial transaction costs but cost dynamics of e-finance were quite complex. Global Electronic Finance [23] and [24], indicated that one must create a fully automated system in order to achieve the full potential of cost reduction.

$\mathrm{H} 2$ : There is an association between security and e-finance.

Security in e-finance is about consumer and investor protection. The issue related includes security, privacy and transparency. Internet is about the "open" system that is easily exposed to interception and fraud. Other than that, the internet had raised many privacy issues in e-finance. Kellermann [30] showed that the improper sharing of information within a financial institution or conglomerate had been the main reason 
behind security problems faced by the worlds. The entry of 30 non-financial entities that have their own information sources on consumers (utilities, retailers) raises additional information-sharing issues. Makelainen [34, 35] mentioned that there was a rapid proliferation of new products, delivery channels, and institutions had allowed transparency, which was easier comparison of prices and financial products, particularly traded securities. Meanwhile, in another study by Madhavan [33] indicated of the emergence of many new products and providers could reduce transparency on the exact service being offered. Given the reluctance of consumers to pay for information on the Internet, for example, information providers typically collected revenues indirectly, including through referred financial transactions. This could result in less transparency.

H3: There is an association between technology architecture and e-finance.

Miskin and Strahan [37] showed that technology architecture played a major part in affecting the growth of e-finance simply because e-finance was highly dependent on technology to carry out its financial services. Use of technology with global externalities involves operational risks, such as computer breakdowns and system failure. These technologies not only function as a new distribution channel of financial services, but a different way to deliver the services. Moreover, technology provides new methods to break the traditional chain of value creation by allowing the production and distribution of financial products to be separated into different businesses (Nieto [40]).

H4: There is an association between adapting global technology to local requirements and e-finance.

UNCTAD [44] mentioned that adapting a global technology to suit the local and the domestic needs was important as it affected the growth of e-finance services in that particular countries. The core of internet technology must be standardized, so that the application needs have to be changed in order to be able to adapt to the local requirements as the internet offered global uniformity and local flexibility.

\section{Data collection method}

A survey is conducted to obtain the required data and information. As compared with other data collection methods, survey allows the collection of huge amount of data in an economical way, without costing too much. The mode of the data collection was with a use of a self-administered survey (mail and online). Respondents answered the survey at their own convenience and there was no need to set up an interview appointment. The respondent is introduced with general purpose of the survey and questionnaire is left for the respondent to fill it out on his or her own. This method is used because it has minimal interviewer influence on the answer, high response rate and inexpensive. The questionnaires were distributed through emails or mails to different companies in Malaysia.

The respondents of this study are targeted on companies that are currently using the e-finance system to deliver their financial services. E.g. banks, insurance companies, brokerage and financial institutions. The sample size consists of about three hundred and fifty respondents from different companies in Malaysia. 


\section{Data analysis}

Reliability analysis

A reliable measure is one in which a respondent responds in the same or in a similar manner to an identical question. To use the reliability analysis, all of the independent and dependent variables are tested to measure whether it is reliable or not. The reliability test above shown that all the independent variables have values higher than 0.7. Therefore, it can be said that all the variables are reliable. Security has the highest cronbach's alpha value result was 0.873 , while adapting global technology has the lowest cronbach's alpha value, which is 0.762 .The finding shows that all the variables are reliable because the cronbach's alpha value was 0.807 .

Table 2 shows the correlation between the e-finance and independent variables. According to the correlation test above, the significance value for security and e-finance is 0.000 , which implies that these two variables are significantly correlated and the hypothesis (H1) is valid. The positive sign indicates a positive direction for the association. In other words, the growth of e-finance will increase if there is high data security. According to Dandapani [16], security needs also underscore the importance of protecting the privacy and confidentiality of the communications between the browser and server, ensuring only the authorized individuals have access to the payments and maintaining the isolation of the computers from the internet.

According to the correlation test above, the significance value for technology architecture and e-finance is 0.000 , which implies that these two variables are significantly correlated and the hypothesis (H2) is valid. The positive sign indicates a positive direction for the association. In other words, the growth of e-finance will increase if there is an increase in the advancement of technology architecture. Previous research, Allen, McAndrews and Strahan [1], stated that internet and wireless communication technologies are having a profound effect on financial services. These technologies are more than just new distribution channels-they are a completely different way of providing financial services.

According to the correlation test above, the significance value for revenue and cost dimension and e-finance was 0.000 , which implies that these two variables are significantly correlated and the hypothesis (H3) is valid. According to Claessens, Glaessner, and Klingebiel [10], the lower the transaction costs can substantially increase competition for providers and cost savings for consumers. The benefits of cheaper financial services will be shared by providers and consumers. With the advent of new types of intermediaries, such as aggregators, consumers can increasingly compare prices for financial services.

Table 2 Summary of correlation analysis of e-finance and independent variables

\begin{tabular}{lll}
\hline Variables & E-finance & \\
\cline { 2 - 3 } & Pearson correlation & Significant \\
\hline Security & 0.937 & 0.000 \\
Technology architecture & 0.980 & 0.000 \\
Revenue and cost dimension & 0.978 & 0.000 \\
Adapting global technology & 0.952 & 0.000 \\
\hline
\end{tabular}


Table 3 Multiple regression analysis

\begin{tabular}{llll}
\hline Variable & B & SEB & Beta \\
\hline Constant & 2.860 & 0.000 & $2.406^{* *}$ \\
Average technology & 0.600 & 0.000 & $2.080^{* *}$ \\
Average revenue and cost dimension & 0.600 & 0.000 & $0.546^{* *}$ \\
Average adapting global technology & 0.200 & 0.000 & \\
\hline
\end{tabular}

Note $R^{2}=1.00 ; F(3,96)=11.88, p<0.01$

${ }^{*} p<0.05 ;{ }^{* *} p<0.01 ;(N=100)$

Table 4 Summary of the hypothesis findings

\begin{tabular}{llr}
\hline No. & Hypotheses & Finding \\
\hline 1. & H1: There is an association between revenue and cost dimensions & Accepted \\
and e-finance & H2: There is an association between security and e-finance & Accepted \\
2. & H3: There is an association between technology architecture and & Accepted \\
e-finance & H4: There is an association between adapting global technology to & Accepted \\
local requirements and e-finance &
\end{tabular}

The significance value for adapting global technology and e-finance is 0.000 , which implies that these two variables are significantly correlated and the hypothesis (H4) is valid. The positive sign indicates a positive direction for the association. In other words, the growth of e-finance will increase, if there is an increase in the adaptation of global technology to meet with local requirements. According to UNCTAD [44], it says that internet offers this amazing capability to reconcile global uniformity and local flexibility. It facilitates cross border links but at the same time create new configurations of networks and clusters.

Multiple regression test

Table 3 shows the result of multiple linear regression analysis of $\mathrm{H} 1, \mathrm{H} 2, \mathrm{H} 3$, and $\mathrm{H} 4$. The analysis found that three variables were significantly related to these hypotheses. The influencer variable was both technology architecture (t-value, 2.406) and revenue and cost dimension (t-value, 2.080) with Beta value of 0.600. On the other hand, adapting global technology has Beta value of 0.200 at 0.000 significance level.

\section{Discussion of findings}

There were four hypotheses tested in this research paper and the results show that all the hypotheses were accepted. Based on Pearson's rank correlation test, all the 
independent variables (security, technology architecture, revenue and cost dimension and adapting global technology to global requirement) does affect the growth of e-finance.

From the findings, we know that security does affect the growth of e-finance. Many people are afraid of the invasion of their privacy and the misused if their personal data and information. Previous research stated that traditions of respect for privacy, and the perceived value of privacy, vary widely among cultures and countries. Some countries ban the private use of encryption, thus ensuring that email transactions are analogous to postcards sent in traditional mail. Law enforcement officials, without notable exception, lobby for access to private electronic communications via "back doors" or other means. But individuals and companies have very good reasons to value privacy and oppose efforts to weaken privacy rights. The wave of identity theft that accelerated in the late 1990s, and the subsequent plundering of personal financial assets and ruin of credit reputations, has received a great deal of media attention in the US. Identify theft alone should serve to justify concerns about privacy of information (Herbst [27]).

From the result of this research, technology architecture does affect the growth of e-finance. Technology architecture has help to make financial transaction a lot easier and faster. According to previous researcher Shahrokhi [43], the nature of the business model dictates the selection of the most appropriate technical platform for the e-finance model. E-finance model that uses dynamic information such as streaming headlines, stock quotes, and other real-time information will require an intricate technical construction and maintenance schedule. Similarly, corporate storefronts that offer interactive, transaction-enabled services and products require an even more extensive technical architecture that is secure and guarantees a certain level of performance. So, if the technology architecture is secure good, it can increase the growth of e-finance.

Other than that, the research findings also prove that revenue and cost dimension can somehow affect the growth of e-finance. With the introduction of E-finance, it can reduce the financial transaction costs Raihan [42]. Previous research by UNCTAD [44] stated that, there is no doubt that Internet has a potential to reduce financial transaction costs. However, the cost reduction potential has often been exaggerated or misinterpreted. Cost dynamics of e-finance are quite complex. For one thing, in order to achieve the full potential of cost reduction, it is important to create a fully automated system, capable of straight-through processing. Furthermore, the costs of migration from legacy to Internet-based architecture are often very high. For that reason, many e-finance enthusiasts favored a pure play model, creating an Internet bank from the scratch. Although technology cost savings were often hypothetical, marketing costs were actual expenditures.

Besides that, it is very important in adapting global technology to local requirement as it does affect the growth of e-finance, can be seen in correlation analysis done in Chap. 4. Other than that, previous research also agreed on this result. Internet technologies are considered global and their core is standardized, but their applications need to be adapted to local circumstances, based on the each nation. Internet offers this amazing capability to reconcile global uniformity and local flexibility. Many successful companies also stress their ability to respond to local requirements in terms 
of their product mix and delivery channels. The need to localize the financial solution is even stronger for the e-finance for SMEs, which for the most part operate within a limited geographical area (UNCTAD [44]).

\section{Limitation}

There are not many e-finance companies in Malaysia as e-finance is still consider new in our country, Malaysia. The companies are scattered all over the country, and it is very hard to get their respond through email. The time given to conduct this survey is very constrained, and it takes extremely long time for the e-finance companies to reply my survey through email.

\section{Future research}

Other than those research methods, variables and factors that had been used and tested for this study, there is a lot more that can be done. Firstly, data should be collected from all over the world and not from a single geographic area of the world because different factors affected e-finance differently in different countries. Secondly, there were still some factors that had not been further researched and studied. Therefore, future research could be emphasized on those factors thus helping us to gain more understanding on e-finance and hopefully getting to find the solutions for the restrictions on the growth of e-finance. Thirdly, studies can be carried out to look into the company's float and collections on sales by using electronic payment systems, and the incentives that could encourage them to be used (e.g., extra discounts on trade credit terms if electronic payment is used). Last but not least, to compare the costs and advantages of traditional lockbox and concentration banking versus electronic payment and collection systems.

\section{Recommendation}

It is clear that from the findings, both providers and customers of e-finance viewed security as a constraint and a concern. Besides that, bad technology architecture was also one of the main concerns of e-finance customers. The concern that the customers faced thus affected the growth of e-finance. So, in order to minimize the concern of e-finance consumers, providers had to strengthen the e-finance security system.

Although encryption techniques and various protocols had been developed by the private sector, evidence on intrusions suggested that these may not be sufficient. Actual penetrations into financial institutions were understated because of the damaging implications for bank's reputations. One approach was to improve authentication that was being employed such as the use of public and private keys. Authorities would have to address these three main issues in designing a country's public key infrastructure. Regulations should be made flexible enough to allow for creative use of new technologies in improving authentication processes. 
Other than that, it is recommended to create adequate regulatory and institutional frameworks. Developing countries need to take a proactive role in developing a robust, flexible regulatory framework for e-commerce and e-finance. It is equally important to ensure effective coordination of government agencies, industry associations and other facilitators. E-finance and e-commerce will succeed only if they created a stable physical and virtual infrastructure of trust, shared by all parties concerned, including public authorities, local and foreign entrepreneurs, financial services providers and customers.

\section{Conclusion}

E-finance is not new. The difference today is that electronic communication and computation is now used much more widely than before. A large number of people have access to the internet and this has vastly changed the opportunities for the use of electronic payments systems, the operations of financial services firms and financial markets. The study indicates that there are four basic misconceptions which were frequently present in the business strategies employed in the earlier stages of the development of e-finance.

While the Internet can reduce financial transaction costs, these gains have often been exaggerated or misinterpreted. It is cheap and quick to create a basic website, designing and implementing a fully functional, industrial-strength application capable of securely accommodating a large number of complex transactions and huge variations in volume is a complex and protracted undertaking. Rather than eliminating possibilities for intermediation, the abundance of information, opportunities and relationships created by the Internet increases the need for new intermediation structures and mechanisms.

Contrary to the view that e-business would revolutionize the financial industry and destroy the incumbent "dinosaurs", the evolution of e-finance clearly demonstrates the advantages of established financial services suppliers, as long they have the capacity to evolve and to embrace the new approaches and technologies. The result of this study has successfully showed that the dependent variable and independent variables are positively correlated and all the hypotheses are valid and accepted. The respondents react quite equally to all the variables as all of variables showed a very strong association. From my research result, all the variables which is security, technology architecture, revenue and cost dimensions and adapting global technology with local requirement does indeed affect the growth of e-finance.

The results shows similar findings as previous researchers, where the variables were said to affect e-finance growth as well. According to Shahrokhi [43], security, technology architecture, revenue and cost dimension and adapting global technology with local requirements are the risks and challenges of e-finance. In this study, the variable "adapting global technology with local requirements" was less focused on and was included in this study as one of the variables. The variable 'adapting global technology' had the highest mean, which meant that it affected the growth of e-finance in Malaysia. Other than that the reliability analysis indicated that all the 
variables were reliable. As a conclusion, this study had achieved its research objectives and thus, was able to contribute its efforts and useful findings to the financial providers and also consumers.

Open Access This article is distributed under the terms of the Creative Commons Attribution Noncommercial License which permits any noncommercial use, distribution, and reproduction in any medium, provided the original author(s) and source are credited.

\section{References}

1. Allen, F., McAndrews, J., \& Strahan, P. (2001). E-finance: an introduction. Journals of Financial Institution Centre, 1-36.

2. Allen, H., Hawkins, J., \& Sato, S. (2001). Electronic trading and its implications for financial systems. Working paper, Bank of England.

3. Allen, F., McAndrews, J., \& Strahan, P. (2002). E-finance: an introduction. Journals of Financial Services Research, 22(1/2), 5-27.

4. Banks, E. (2001). E-finance: the electronic revolution. London: Wiley.

5. Baxter, W.F. (1983). Bank interchange of transactional paper: legal and economic perspectives. Journal of Law \& Economics, 24, 541-588.

6. Bedrikow, R. (2002). E-finance in Brazil. Paper presented at the UNCTAD E-Commerce.

7. Berger, A.N., Demsetz, R.S., \& Strahan, P.E. (1999). The consolidation of the financial services industry: cause, consequences and implications for the future. Journal of Banking and Finance, 23, 94-135.

8. Boot, A., \& Thakor, A.V. (2000). Can relationship banking survive competition? Journal of Finance, 55(2), 679-714.

9. Business Week (2001). Online Money trading takes off. 3 September.

10. Claessens, S., Glaessner, T., \& Kliengebiel, D. (2000). Electronic finance: a new approach to financial sector development. Journal of World Bank, 431, 1-97.

11. Claessens, S., Glaessner, T., \& Kliengebiel, D. (2001). E-finance in emerging markets: is leapfrogging possible? World Bank Financial Discussion. Paper No. 7.

12. Claessens, S., Glaessner, T., \& Kliengebiel, D. (2003). Electronic finance: reshaping the financial landscape around the world (pp. 1-44).

13. Christiansen, H. (2002). Electronic finance: economics and institutional factors. Journals of Financial Market Trends, 81, 45-79.

14. Credit Suisse First Boston Global Bank Team (1999). Special Internet banking review. New York.

15. Crowther, J. (2006). Personal UK e-finance player moneynet uses technology to monitor and increase online business. Journals of Financial Services Marketing, 272-276.

16. Dandapani, K. (2008). Growth of e-financial services: introduction to the special issues. Journals of Managerial Finance, 34(6), 361-364.

17. Domowitz, I., \& Steil, B. (1999). Automation, trading costs, and the structure of the securities trading industry. Brookings-Wharton Papers on Financial Services, 2, 33-92.

18. Hancock, D., Humphrey, D.B., \& Wilcox, J.A. (1999). Electronic payments: the roles of consolidation, economies of scale and technical change. Journal of Banking and Finance, 23, 391-421.

19. Evans, D.S., \& Schmalensee, R. (1999). Paying with plastic: the digital revolution and borrowing. New York: MIT Press.

20. Faegre \& Benson (2000). The e-finance revolution. 1-4. Financial Economist, World Bank; and D. Klingebiel, World Bank. Electronic finance: a new approach to financial sector development?

21. Frix, P. (2002). The commission on enterprise, business facilitation and development on its sixth section. Geneva.

22. Gewei, Y., \& Keesling, G. (2006). E-finance: The CCMP model. Journals of Business Performance Management, 8(1), 37-46.

23. Global Electronic Finance (2001). Internet and securities markets. Financial Issues Working Group, February.

24. Global Electronic Finance (2001). Internet and payment systems. Financial Issues Working Group, March. 
25. Hu, J., Ohshima, M., \& Zhong, N. (2006). Developing grid-based e-finance portals for intelligent decision making. Journals of Department of Information Engineering, Maebashi Institute of Technology $1-2$.

26. Gewei, Y., \& Keesling, G. (2006). E-finance: The CCMP model. Journals of Business Performance Management 8(1), 37-46.

27. Herbst, A. F. (2001). E-finance promises kept, promises unfulfilled and implications for policy and research. Journal of Global Finance 205-215.

28. Indjikian, R. (2002). E-finance for SMEs: global trends and national experiences. Journals of Electronic Commerce, 1-38.

29. Kumar, S. E-finance in a developing country like India, 1-11.

30. Kellermann, T. (2002). Mobile risk management: e-finance in the wireless environment. Journals of Financial Sector, 1-28.

31. Levinsohn, A. (2001). The wild wired world of e-finance. Journals of Strategic Finance, 28-32.

32. Levinsohn, A. (2001). Few flock to e-finance. Journals of Strategic Finance, 69-70.

33. Madhavan, A. (2000). In search of liquidity in the Internet era. Paper presented at the Ninth annual financial markets conference of the federal reserve bank of Atlanta.

34. Makelainen, S.I. (2006). From B2C to C2C E-commerce, 1-18.

35. Makelainen, S.I. (2006). From B2C to C2C E-commerce, 1-18.

36. McAndrews, J., \& Stefanadis, C. (2000). The emergence of electronic communications.

37. Mishkin, F.S., \& Strahan, P.E. (1999). What will technology do to the financial structure? In R. Litan \& A. Santomero (Eds.), The effect of technology on the financial sector. Brookings-Wharton Papers on Financial Services (pp. 249-287).

38. Mor, N. Executive Director, ICICI Bank, India. E-finance for development: an Indian perspective.

39. Moore, R., Muller, A., Muller, R., \& Temmen, K. Adapting e-finance web server farms to changing market demands, 1-6.

40. Nieto, M.J. (2003). Reflections on the regulatory approach to e-finance, 90-97.

41. OECD (2001). Understanding the digital divide. Oliveira, Antonio C.B; Executive Director, Banco Itaú, Brazil. E-Finance for SMEs in Brazil on Relationship Banking. Journal of Applied Corporate Finance (Spring), 40.

42. Raihan, A. (2001). The state of e-finance in developing countries: Bangladesh perspective, 1-11.

43. Shahrokhi, M. (2008). E-finance: status, innovations, resources and future challenges. Journals of Managerial Finance, 34(6), 365-398.

44. United Nations Conference on trade and Development (UNCTAD) (2002). E-commerce and development report (Part 1). New York and Geneva.

45. Zekos, G.I. (2003). Cyberspace and e-finance. Journals of Hertfordhire Law, 2(1), 31-44.

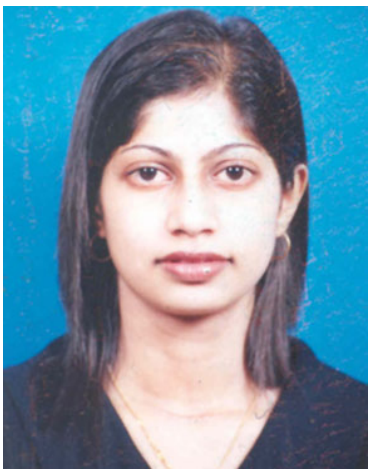

Kogilah Narayanasamy was awarded Bachelor of Business Administration (Hons) from Ohio Northern University, USA and Master of Business Administration (Information Technology) Multimedia University, Malaysia. Her interest is in e-commerce application and Online Business. 


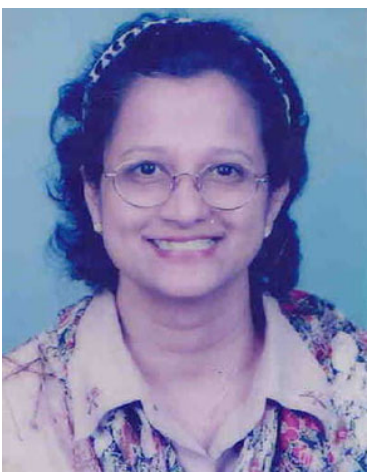

Devinaga Rasiah is a lecturer with the Faculty of Business \& Law. Her MBA is from University of Wales, UK. Her research interests are in commercial and investment banking. Apart from these, she is also interested in topics relating to internal controls, Automated Teller Machine services and self service technologies and bank management.

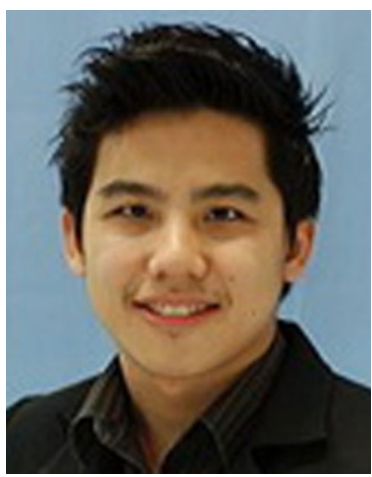

Teck Ming Tan (Degree from Multimedia University) is an assistant lecturer at Centre for Diploma Programmes, Multimedia University, Melaka Campus, Malaysia. His research interests include brand equity, online branding, advertising, financial services and consumer research. 